\title{
Using Your Local Community Resources: Public Access Cablevision Channels
}

\author{
By Linda Bartrom
}

B eginning a TV/Media Class is a barren wasteland. What do you do for the computers, the cameras, the switching board, the external hard drives, the lights, the microphones... the necessary equipment to train your learners on?

Although content and terms and technical concepts abound, a television production course is denied existence if there is no production. Too many students emerge from courses (and this applies beyond the media field) with lots of book-learning and little training due to lack of equipment. For TV production students the result is that they can define "white-balance" but cannot do it; they can describe a tripod but cannot secure a camera to it; they can clarify what "C.G." means but cannot use a C.G. board to prepare sub-titles. Schools do not house television studios and outfitting one is a lifetime enterprise on a school budget, especially these days.

Fund-raising, an earlier column, can purchase basic equipment for short-subjects and their editing, but the production studio itself is another matter; and it cannot be a oneday "field trip" if your learners are to emerge with the skills your course promises: Production.

So where do you turn? Make a sharp right at your computer, sit down, and locate the nearest Public Access Cablevision Station. That's right. Because YOU are the reason these stations exist. Public Access means exactly what it says, and a component of every station's required goals is an educational/training arm. Your students, through use of their facilities, actually help small stations fulfill their required activities.

The first step is to get to know the station producer. He or she may have another title, but there will be an in-house person, often part-time, whose job is to train the public on the equipment so they can produce their own shows. Get acquainted by phone, make an appointment, then visit the station in person. Go slow. I suggest a training workshop (conducted in a couple of days by the producer) in the summer for your "studio crew," to avoid huge outlays of time in the fall to train your students individually.

Then set up a time once a month to produce a show. It can go live if your talent is good enough, but better to record to an external hard drive (\$250), which you can take back to school to edit. You will have already divided your class into talent, studio crew, and editors, so now your editors jump in.

My students produce a weekly show, and yours will too eventually, but once a month to begin with will be a good starting point plus it won't require too much of the producer's studio time. Cultivate that relation- ship for a year and then consider a bimonthly show.

Off-campus passes are required during the school day which will require administrative permission; on the other hand, although after-school production is easier administratively, it will require volunteer time on your part. This is your call. Based on a monthly show, a lesson plan suggestion allocates the first week for script development, the second for rehearsal, and the third week for production. In the final week:

1. Editors begin post-production on the just-finished show.

2. A chapter in your text is covered.

3. A film relevant to movie history is screened.

4. The finished show from the previous month is viewed and critiqued.

Then it's time for delivery to your Cablevision Channel for transmission; be sure to advertise the transmission times to your school community!

So there you are: fully outfitted, up and running from day one. In truth, Public Access Cablevision Stations are the most underused and undervalued resource in Media Education. Public Access is required by your government, for training of your city's citizens, for transmission of your community's productions. Use it, teachers, it belongs to you! 